Tran, J., Wong, M., Wright, E.K., Fa'avae, J., Cheri, A., Wat, E., Camacho, K.L., \& Foo, M.A. / Californian Journal of Health

\title{
Understanding a Pacific Islander Young Adult Perspective on Access to Higher Education
}

\author{
Jacqueline Tran ${ }^{1}$, Michelle Wong ${ }^{1}$, Erin Kahunawaika'ala Wright ${ }^{2}$, Joe Fa'avae ${ }^{1}$, Ashley Cheri ${ }^{1}$, \\ Eric Wat ${ }^{3}$, Keith L. Camacho ${ }^{4}, \&$ Mary Anne Foo ${ }^{1}$ \\ ${ }^{1}$ Orange County Asian and Pacific Islander Community Alliance \\ ${ }^{2}$ University of Hawai i- Manoa \\ ${ }^{3}$ Special Service for Groups, Research and Evaluation Unit \\ ${ }^{4}$ University of California, Los Angeles
}

\begin{abstract}
The Pacific Islander (PI) community suffers disproportionately from illnesses and diseases, including diabetes, heart disease and cancer. While there are tremendous health needs within the PI community, there are few health care providers from the community that exist to help address these particular needs. Many efforts have focused on health care workforce diversity to reduce and eliminate health disparities, but few have examined the issues faced in the health care work force pipeline. Understanding educational attainment among PI young adults is pivotal in speaking to a diverse health care workforce where health disparities among Pacific Islanders (PIs) may be addressed. This paper provides an in-depth, qualitative assessment of the various environmental, structural, socio-economic, and social challenges that prevent PIs from attaining higher education; it also discusses the various needs of PI young adults as they relate to psychosocial support, retention and recruitment, and health career knowledge and access. This paper represents a local, Southern California, assessment of PI young adults regarding educational access barriers. We examine how these barriers impact efforts to address health disparities and look at opportunities for health and health-related professionals to reduce and care for the high burden of illnesses and diseases in PI communities.
\end{abstract}

(C) 2010 Californian Journal of Health Promotion. All rights reserved.

Keywords: Pacific Islander young adult, community-based participatory research, educational access, pipeline, health careers, and health disparities

\section{Introduction}

\section{Background}

In California, there reside nearly 246,000 Pacific Islanders (PIs) (US Census, 2000). Among this population, health care needs are disproportionately high, especially with respect to chronic disease; PIs have some of the highest rates of cancer, obesity, heart disease, hypertension, and diabetes yet little access to health care. All-site cancer mortality rates for Native Hawaiians are the second highest in the U.S., following African Americans; specifically, Native Hawaiian women have the highest mortality rate from breast cancer in this country (Miller and colleagues, 1996; Office of Minority Health Quick Facts, 2008). Locally, Native Hawaiian and other PI women in Orange County were over 2.4 times more likely to have latestage breast cancer at the time of diagnosis (Marshall and colleagues, 2008). Marshallese women have higher breast and cervical cancer rates overall in the U.S (Palafox and colleagues, 1998). Data drawn from American Samoans living in Hawai' $\mathrm{i}$ and Los Angeles County in California revealed that American Samoan males were 10 times more likely to have nasopharyngeal cancer, seven times more likely 
Tran, J., Wong, M., Wright, E.K., Fa'avae, J., Cheri, A., Wat, E., Camacho, K.L., \& Foo, M.A. / Californian Journal of Health

to have liver cancer, and three times more likely to have stomach cancer than their White counterparts (Mishra and colleagues, 1996).

While it is clear that PIs face disparate health and health conditions, there are few health care providers from the community to help address these particular needs. Many efforts have focused on health care work force diversity to reduce and eliminate these gaps in health care delivery and to reduce health disparities (Strayhorn and Demby, 1999, IOM Report 2003, Sullivan Commission 2004, Marcelin and colleagues, 2004; and HRSA, 2006). These efforts are imbued with a belief that increasing the number of under-represented minorities in health careers will (1) create more culturally competent approaches to working with minority communities, (including language-appropriate health care materials and culturally-appropriate research methodologies); and (2) create an infrastructure to support diverse health initiatives. While pipeline programs have been developed to foster opportunities among minority groups, few have focused on PIs, with the exception of programs in Hawai $i$ focused on Native Hawaiians such as 'Imi Ho'ola at the University of Hawai i's John A. Burns School of Medicine and the Native Hawaiian Health Scholars and Na Liko Noelo Programs at Papa Ola Lokahi. Hawai i also leads the way in developing culturally competent approaches to working with PIs (again mostly Native Hawaiian) that engage and recruit indigenous individuals; these programs have focused on integrating health care and health education curricula that "understand and apply indigenous people's paradigms of health, knowledge, science and research" (Santos and colleagues, 2001; Tsark 2001; O'Sullivan and Lum, 2001; Hughes and Higuchi, 2004; Pearsall, 2007; Ribiero and Harrigan, 2006; and Fong and Aitaoto, 2008). However, similar efforts on the continental United States remain sparse.

\section{Education Characteristics of Pacific Islanders}

Education is viewed as a tool for community and social change. For minority communities, education is a central source of empowerment. Given the dire socio-economic conditions of PIs, education is viewed as a viable means to transform the status quo. Furthermore, the community has also made a link between its health status and its ability to increase the number of PIs in health careers, which hinges on a minimal threshold of educational attainment.

In the U.S., almost 1 in $4(24.4 \%)$ people who are 25 years and over had at least a bachelor's degree in 2000 . In contrast, only $13.8 \%$ in the PI population had reached this educational attainment. This figure is slightly lower in California (12.6\%), including both Los Angeles (12.7\%) and San Diego (12.7\%) counties. PI students may be graduating from high school at a similar rate to the general population, but they were not enrolled in college. Or if they were, they were not as likely to matriculate. Only $29 \%$ of PIs between the ages of 18 and 24 are enrolled in a college or university, which is comparable to African Americans. In contrast, $39 \%$ of non-Hispanic whites and $57 \%$ of Asians in that age range are enrolled in college (UCLA Asian American Studies Center, Census Information Center, 2007). Consequently, only $4.1 \%$ of all PIs in the U.S. hold a graduate or professional degree, as compared to $18.5 \%$ of the general population and $17.5 \%$ of Asian Americans (Lai and Arguelles, 2003).

Educational attainment gaps are attributed to multiple factors that become compounded over time (Lee and Kumashiro, 2005). By the time they reach college, many students have already faced years of inequitable access and resources. While there have been some minimal gains in "educational aspirations" over the years for minority communities, there still remains a significant gap between PIs, Native Americans, African Americans and their White and Asian American counterparts (Kao and Thompson, 2003). Some key themes associated with this gap are: achievement/motivation, parent socialization, parent/family-child expectations toward academic achievement, parent/familyschool participation and involvement, literacy and language differences, degree of historical consciousness (attitudes towards colonization), and political and economic dimensions as identified by Kao and Thompson. Other researchers have found that for PI students, additional barriers exist including: minimal 
Tran, J., Wong, M., Wright, E.K., Fa'avae, J., Cheri, A., Wat, E., Camacho, K.L., \& Foo, M.A. / Californian Journal of Health

representation of PI faculty and staff (also noted as instructional issues or the school structure); lack of support networks; inadequate college preparation for young adults; socioeconomic status; challenges balancing family obligations and education; family background (which may include family structure, family socioeconomic status and migrant status); gender; and stereotypes and identity (Ah Sam and Robinson, 1998; Onikama and colleagues, 1998; Tsutsumoto, 1998; Kawakami, 1990; Lee and Kumashiro, 2005; and Miyamoto, 2005). All these factors reflect the interconnected nature of family, home, school, and community (Benham, 2006). Important to the success of young adults is balancing all these aspects to ensure successful educational attainment and matriculation of young adults .

Models have been developed, much like health pipelines within education, to promote workforce diversity. Such programs have increased the number of culturally concordant instructors and school administrators (Lee and Kumashiro, 2005). A specific PI model for greater cultural understanding and the interconnection of family, school and community is the Kamehameha Early Education Program (KEEP). This program and others like it have shown that culturally compatible education has yielded success in educational attainment and educational pursuits of higher education (Lee and Kumashiro, 2005). As a result, concerted efforts to address educational attainment and health care work force diversity may synergistically contribute to an increase in culturally concordant health care providers working to address health care disparities.

According to the U.S. Census Bureau, most PIs are employed in service related industries and very few are in management or professional occupations, including health care (US Census, 2004). Among single race PIs in California there are only 39 physicians and surgeons and 425 registered nurses (US Census, 2000), however a majority live and work in Northern California (Alameda and Sacramento counties) with only about $30 \%$ of these providers living and working in Southern California, which has the largest PI population. Health care workforce diversity programs have been developed to help engage, recruit, retain and matriculate more diverse health and health care professionals. While programs have fostered opportunities among minority populations, few have focused on PIs; in particular, limited efforts have been made to address the lack of available, eligible students to engage in these opportunities. The Pacific Islander Health Careers Pipeline Program (PIHCPP) was established in 2007 to increase access and preparation to health and healthrelated careers for PI young adults. In developing our strategy, we identified barriers to educational attainment that would contribute to the lack of success of pipeline programs. The purpose of our study was to assess the strengths and challenges faced by young adults in accessing higher education and health career opportunities among PIs in Southern California using a community-based participatory (CBPR) approach. By better understanding the issues faced by PI young adults, PIHCPP is better informed to develop and address a PI health career pipeline, to help reduce and eliminate the burden of chronic diseases disproportionately impacting the PI community through the promotion of PI health and health-related professionals. Our study contributes to the literature information from the perspective of young adult PIs on the continental United States, particularly young adults in Southern California.

\section{Methods}

In 2007, a community-based participatory research effort was initiated to conduct a needs assessment of educational concepts among PI young adults in Southern California. The needs assessment, conducted from March to December 2008, provided in-depth, qualitative data about the various health and educational challenges among PI young adults in Southern California, particularly in Los Angeles, Orange and San Diego Counties. The semi-structured interviews and focus groups were confirmatory. Both interviews and focus groups were to validate findings across different types of individuals in Southern California, as well as for comparison to other research findings focused on PI youth and young adults noted previously. Interviews and focus groups yielded similar information 
and mirrored research findings from other studies of PI youth and young adults, mainly in Hawai i.

\section{Participants}

In total 11 key informant interviews and seven focus groups with 38 participants were conducted. PI young adults entering, in, or having completed college were recruited for the study as they were the ideal candidates to share the educational attainment experience. Table 1 provides detailed demographics on key informant and focus group participants.

\section{Table 1}

Focus Group and Interview Participant Demographics

\begin{tabular}{|c|c|c|c|c|c|c|c|c|c|c|}
\hline \multirow[t]{2}{*}{$\begin{array}{l}\text { Community Focus } \\
\text { Groups* }\end{array}$} & \multirow[t]{2}{*}{$\begin{array}{l}\text { Age of } \\
\text { Participants }\end{array}$} & \multirow[t]{2}{*}{$\begin{array}{l}\text { Number of } \\
\text { Participants }\end{array}$} & \multicolumn{8}{|c|}{ Ethnicity } \\
\hline & & & 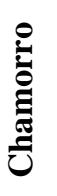 & 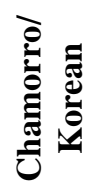 & 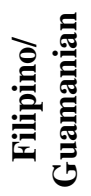 & 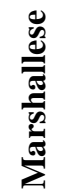 & 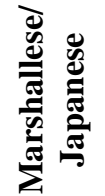 & 䒴 & 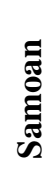 & 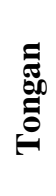 \\
\hline
\end{tabular}

\begin{tabular}{lllllllllll}
\hline $\mathrm{A}$ & $21-33$ & 10 & 4 & 1 & 5 & 0 & 0 & 0 & 0 & 0 \\
\hline $\mathrm{B}$ & $15-23$ & 9 & 0 & 0 & 0 & 8 & 1 & 0 & 0 & 0 \\
\hline $\mathrm{C}$ & $18-21$ & 2 & 0 & 0 & 0 & 0 & 0 & 0 & 0 & 2 \\
\hline $\mathrm{D}$ & $14-23$ & 9 & 0 & 0 & 0 & 0 & 0 & 0 & 0 & 9 \\
\hline
\end{tabular}

\begin{tabular}{lllllllllll}
$\mathrm{E}$ & $\mathrm{n} / \mathrm{a}$ & 5 & 1 & 0 & 0 & 0 & 0 & 1 & 3 & 0 \\
\hline $\mathrm{F}$ & 16 & 1 & 0 & 0 & 0 & 0 & 0 & 1 & 0 & 0 \\
\hline $\mathrm{G}$ & $13-15$ & 2 & 0 & 0 & 0 & 0 & 0 & 2 & 0 & 0 \\
\hline
\end{tabular}

\begin{tabular}{|c|c|c|c|c|c|c|c|c|c|c|}
\hline Interviews** & $18-23$ & 11 & 0 & 0 & 0 & 1 & 0 & 2 & 7 & 1 \\
\hline Total participants & & 49 & 5 & 1 & 5 & 9 & 1 & 6 & 10 & 12 \\
\hline
\end{tabular}

*Participants were Pacific Islander young adults who were high school or college students.

**Participants were Pacific Islander key informants who were leadership in campus groups or recent alumni with leadership roles in campus groups

\section{Sampling}

We gathered a convenience sample identified through key community leaders and organizations across three counties to recruit key informant interviews and focus group participants. Community based agencies working in health education and health promotion with Pacific Islander communities served as conduits to identify participants for the study. We sought to recruit a diverse sample of participants reflecting 5 of the largest local PI populations, notably Chamorros/Guamanians, Marshallese, Native Hawaiians, Samoans and Tongans from Los Angeles, Orange or San Diego counties. Participants ranged in age from
13 to 33 years. Since we relied on a convenience sample, we did not discourage participation from some young adults, younger than general age for college entry. In particular, we encouraged the participation to ensure a diversity of representation by ethnic groups in Southern California. It was also important, as a CBPR effort to engage and involve community; as such we felt that the contributions of the young adults, younger than the typical age for college entry, were also significant to our study effort in understanding opportunities for higher education among PI young adults. As well, some of our informants and participants were older than the average college-aged student or graduate; these 
individuals were included to reflect the nontypical experience of PI young adults to get into college and through matriculation, emphasizing that the process is not the usual 4-year path.

Interviews were conducted with 11 key informants ranging from 18 to 23 in age. Key informants were students in college serving in leadership roles in student groups on campus or recent alumni who were student leadership in student groups. These individuals were separated from the focus groups which were held with young adults from the PI community. Participants in focus groups were ages 13 to 33 and included young adults who were either students in high school or college. Please note table 1 for participant demographics. Information from all focus groups and key informant interviews were considered for analysis.

\section{Interviews}

Interviews consisted of face-to-face, one-on-one sessions with a standardized questionnaire. Interviews were conducted in English, audio recorded, and transcribed. Interviews took from 15 to 47 minutes with an average interview time of 27 minutes.

\section{Focus Groups}

Seven focus groups were conducted and organized according to the 5 ethnic subgroups. The goal was to have 6-8 participants per group and to gather representation from all three counties. In total seven groups were held with 38 participants; no further groups were held due to saturation. In particular, focus group F only had one participant, while not the typical size for a focus group, we included this interview to ensure adequate ethnic representation among study participants. Due to the nature of convenience sampling, we relied on the community and cultural relationships we developed; thus, we did not want to offend those interested in participating in our study and honored their participation with inclusion in the study data. Focus group sessions took from 31 to 116 minutes with an average session time of 68 minutes.
Focus groups were utilized as they mirrored the "talk story" format that is culturally salient in the PI community. The sessions were facilitated by a moderator with a standardized guide. Moderators received Institutional Review Board (IRB) and focus group facilitation training. Focus groups were conducted in English, audio recorded, and transcribed.

IRB approval was provided for this study from the Special Service for Groups (SSG) Community IRB. As a community-based participatory research project, it was important to have this community-led and based IRB review the study. Interview guides as well as consent and assent forms were created and approved by SSG's IRB, approval number 2008001. Incentives were provided to all the focus group participants to honor the time they spent sharing their personal experiences.

\section{Measures}

The interview and focus group guides were developed and framed by the extant literature on factors influencing the educational gap (Ah Sam and Robinson, 1998; Onikama and Colleagues, 1998; Tsutsumoto, 1998; Kawakami, 1990; Kao and Thompson, 2005; Lee and Kumashiro, 2005; and Miyamoto, 2005). All participants were asked questions regarding present and past experiences in education, family, culture, community/neighborhood, friendship groups, family educational attainment, their own educational and career aspirations, and suggestions on how to improve the barriers, if any were identified. These themes and concepts were then used to facilitate the data analysis. The data was analyzed by grouping core themes and coding these themes through an inductive and iterative process (Bernard 2006, and Miles 1994). The research team (four of the study authors) independently analyzed the interview and focus group data and noted major themes and concepts of analysis through inter-rater consensus development, using the emergent codebooks as guides. The research team, along with the Community Advisory Board, met several times to discuss the independent analyses and to identify similar associations 
Tran, J., Wong, M., Wright, E.K., Fa'avae, J., Cheri, A., Wat, E., Camacho, K.L., \& Foo, M.A. / Californian Journal of Health

between themes and coded segments of the text, as well as new themes not noted in the preliminary codebooks. Any discrepancies or disagreements in interpretations of certain codes or themes were further clarified through these discussions to confirm the validity of the findings (Denzin 2000 and Strauss 1990).

\section{Results}

Interviews and focus groups provided detailed information about the issues that PI young adults face in obtaining educational access. Common concerns and needs were raised during the PI young adult informant interviews and focus groups. Key recurring themes were socioeconomic status, social support, culture, educational resources and stereotypes/identity. These themes were similar to those cited in extant literature (Ah Sam and Robinson, 1998; Onikama and Colleagues, 1998; Tsutsumoto, 1998; Kawakami, 1990; Kao and Thompson, 2005; Lee and Kumashiro, 2005; and Miyamoto, 2005).

\section{Socioeconomic Status}

Study participants came from a variety of different environmental settings; some informants described their neighborhoods as being low-income, in some cases unsafe and also ethnically diverse. The school environment was described as often mirroring the surrounding neighborhoods. Households were typically described as large within which both immediate and extended families reside.

When speaking of socio-economic status, informants shared some of the community/environmental issues that impacted their lives. Some shared the challenges of living in communities where they faced racial hostility, the presence of gangs, as well as socio-economic challenges. Informants expressed that their school environment reflected the unsafe, gang ridden surrounding environment. They shared how these environmental factors influenced education and often times placed a lower emphasis on it.
"So we live in an environment where there is a lot of racial hostility to...we come from neighborhoods with the mentality that you look out for yourself and your family first and you know no one else really matters..."

Informants consistently mentioned that they faced competing priorities between work, school, and in some cases, church. Informants often lived in households where there was little support from parents and differing perspectives on priorities, leaving the PI young adults pressured to decide one or the other, between family and school. This was a clear reflection of socioeconomic status with the community.

"Well as far as, my brother, he's like mostly he's the man of the house so he makes sure that we all get our education and but my mom, her priority is different, like church is number one. That's the, that's the struggle I feel like with other Tongan families."

Familial expectation was also shared as an issue that was related to socioeconomic status. Informants expressed the expectation of their families to get a job and begin working to support the family after graduating from high school, thus, delaying or perhaps eliminating the opportunity to pursue a higher education.

"Um, well my parents, they expect, I mean we have high, uh, since my brother and sister didn't go to um, college and stuff, they expect me to, um, get that knowledge to pay everything for them and stuff, so, the expectations are high in my family."

Previous studies by Kao and Thompson and Lee and Kumashiro also noted socioeconomic status and its role in impacting educational attainment. In particular, the family structure, as related to socioeconomic status, was mentioned; single parent homes, familial expectation, and social support were inherently linked to educational attainment (Onikama, 1998; Kao and Thompson, 2005; and Lee and Kumashiro, 2005). Family socioeconomic status may influence the 
Tran, J., Wong, M., Wright, E.K., Fa'avae, J., Cheri, A., Wat, E., Camacho, K.L., \& Foo, M.A. / Californian Journal of Health

neighborhoods and communities that young adults live in and thereby impact the type of education that they may receive.

\section{Social Support}

Informants expressed that they were not receiving the support that they needed to pursue higher education and spoke of the importance of and need for role models for themselves. As students involved in their respective PI student clubs, they were able to seek out support from others like themselves.

Informants shared that it was important to be able to have a social support network and how such networks increase awareness of other available resources, including their own campus career centers. Informants also believed that programs initiated through student groups in outreaching to the community were important. This helped to let other students know what was available and that there were students to contact and learn more from. An informant shared how they and their peers were told to focus on sports but that academic merit wasn't discussed and their peers missed potential opportunities. So they discussed how this misinformation and negative modeling can lead to missed opportunities.

"Um, a lot okay a lot of them stress more on sports. And without the grades, they can't go; you know and pursue sports at the collegiate level. So they really miss that whole, you know, it's a misconception and I think a lot of parents don't understand that, until it's too late."

Without mentors and guidance, some students resort to working because they believe they have no other choice.

"Very few, very few of them will see themselves going to college. I've had, just many conversations with the kids being involved with PI Club and um, you know it's sad, a lot of them think that if they don't go to a real college that, you know, they just might as well start working. It's not, you know if they can't get a scholarship, or if they can't get the grants that they need, and um, some of them don't even know about grants, I don't think...if it wasn't for the advisors and the counselors, they wouldn't know about grants and that there's other ways to pay for college, they just don't know about it so they give up so, they give up so easily. And um, they're so tempted to be drug dealers after high school, or you know, doing something, some criminal activity rather than taking the energy to figure out how to pay for college...that doesn't have anything to do with sports."

In addition to role modeling and mentorship, especially from other PIs, informants believed that high school outreach activities would be highly beneficial for students seeking higher education. These activities would provide students an avenue through which to meet other PI students, become part of a larger social support network, and encourage one another to persist in pursuing higher education.

"But something I wish that would have helped me would have been a high school outreach, like the one that we just brought up, just to, just to be able to socialize with other PI's in other, fellow PI's in the higher education and also a mentor, would have been nice, for me, someone who I could have identified with...in school and... I think that's about it or just someone I to talk to about school in general."

"My recommendations would be just to implement, um, those high school outreaches that we've had and also um, being, having a mentor, a mentor for probably the majority of PI's to see, to allow them to see what they need to do, and gain resources from that person. Also having workshops about um, self, self, I don't know, some workshop that will um, focus on them themselves, yeah, like self exploration like for them to deal with themselves instead of trying to put family first but they should try to put themselves first and see and go from there."

Lack of familial support was also a consistent theme. Due to different challenging circumstances, parental involvement is limited and in some cases, nonexistent in homes. 
Tran, J., Wong, M., Wright, E.K., Fa'avae, J., Cheri, A., Wat, E., Camacho, K.L., \& Foo, M.A. / Californian Journal of Health

Informants expressed that there is a lack of role models, support and mentorship- in the home, within peer support networks, and at school.

“...my mom's like into like worldly things like we should have better cars, better clothes and everything. That's how my brother ran off the line and went the other way. And um, like um, like, I know how my brother feels, cuz um, my mom you know (starting to cry) she's not really there. I only look up to my older sister. It's just, um, its hard cuz my dad is not there cuz he passed away. I try to look up to my older brother but you know he's not there like fully there. So my sister's the only like role model or something like that. But it's hard...living in my house. Everybody thinks that we're ok and everything...but it's, it's not. We have arguments like every day. So... that's how my family is."

Within peer support networks, informants express that their friends and other PI students are not pursuing higher education, which has a significant influence on their own educational pursuits.

"The people I hung out with didn't go to college."

Onikama speaks very specifically to familial support. In particular she addresses how culturally PI parents do not see themselves as stakeholders in education and without being assigned this role by a principal or teacher, whom they revere, they will not intervene in the domain of school. They believe that their role is to educate their children at home and not to intervene in the matters at school; as a result it may appear that they are not providing support to their children. Students also alluded to the need for outreach efforts and programs to help understand the complexity of higher education. This currently exists in the form of recruitment and retention programs, especially in medical schools; it may be that these resources need to be made more apparent to PI communities.

\section{Culture}

Young adult informants discussed culture as both a strength and barrier in supporting their efforts. Informants mentioned that one of the positive aspects of their experience in the educational system was having the opportunity to be involved with the PI community and in turn, take pride in their culture while connecting with other young PI adults. At the same time,

informants shared about the need to prioritize family obligations, to provide support and to tend to household needs. As a result, some young adult informants believed that culture posed a potential barrier.

"It's a beautiful thing that you stick with your family, but that's the thing you have to stick with your family...you can't go off, 'oh I want to go study abroad" "

Young adults specifically shared how education was an opportunity to develop and discover oneself; including one's identity, but that sometimes family did not see the merit in this. It was perceived as a selfish goal and that it did not contribute to the greater good of the family unit.

\section{Educational Resources}

Young adult informants spoke about a need for information and resources and possibly finding such resources through social networks. However, others noted that even with resources, peers lacked motivation and drive for success, some believing that higher education was not an option directed to them.

"If anything, they were just as smart, like that was, that was the thing that was really, um, sad to me. A lot of my friends who were probably just as smart or smarter, they didn't, just the whole mindset wasn't there to go to college."

"I think they see education as an option or not really an option for them. I think youth see education as getting your high school diploma, that's all they can do....(education) is something they can't attain - You know like go to collegethat's not for me. You know I have to graduate and help my family out."

Support within schools is lacking as well, and stereotypes within the school system may influence PI students' educational success. Miyamoto and Lee and Kumashiro discuss how 
Tran, J., Wong, M., Wright, E.K., Fa'avae, J., Cheri, A., Wat, E., Camacho, K.L., \& Foo, M.A. / Californian Journal of Health

there is a lack of understanding about PI students and their cultures and this leads to stereotypes that form young adult identities. Often, educational attainment is not associated with this identity, as noted by participant comments.

"But I realize like our counselors, like they don't expect...they don't have high expectations for Polynesians. When I went there, I was, I was, I had a good GPA so she was like oh, you're, oh you should go to honor classes you need like... and but then she goes, how come you're not in sports? And I said I don't want to play sports and then she's like, well you can get a scholarship by that and she's like saying every Polynesian plays sports she was saying like I had to play sports just to get out, to get out of, like to, to get a scholarship somewhere and I was like I know what she was saying was a good thing but how she said it to me it was like..."

Many of the informants recognized that there is an abundance of resources available, but there is also a great disconnect between the resources available and the way they are disseminated into the community, including young adults and their parents. Many PIs depend on sports to carry their way through college and if not sports, they lose interest in college all together. Often in the athletic realm, students are guided and provided resources to navigate the educational system, however if they get injured no one is concerned with what happens to them and whether they remain and succeed in college. Without these guiding resources, students get lost and this may lead to dropout.

Overall young adult informants shared that creating outreach programs to PI young adults and having PI role models are effective tools to help young adults engage in, pursue, and succeed in college. Lee and Kumashiro note that having culturally concordant role models, for example as instructors and school administrators, also lends to student support and success, as noted by study participants. Young adult informants also spoke about the need to engage parents to be supporters. In particular, they wanted resources to help parents understand the educational process, since many are first generation families and, understanding the process can be overwhelming. This concept of parental/familial involvement in education was also supported by Onikama in her studies. Young adult informants also felt that working together to ensure resources and support services are available will help young adults achieve academic success. Informants felt strongly that in order to reach the PI community with the appropriate educational resources, the key is to start early in educating and instilling into the PI community the importance of education. More importantly, the community needs to be informed about how culture is not lost, but rather, valued and can be integrated into the process of pursing (higher) education. These sentiments echo Benham's work which discusses the importance of integrating culture and community into education.

\section{Stereotypes / Identity}

Informants felt strongly that existing stereotypes of PI young adults make it difficult to succeed in education- stereotypes are so prevalent that PIs believe them themselves. As a result, stereotypes are perpetuated within the PI community and also put an added pressure on young adults to combat these stereotypes while simultaneously finding as well as establishing their identity as PIs.

“...they dropped out because they were actually pregnant or, you know, um, not interested in school. And I just see them you know in the streets. And like I tell them that oh, I am still in school. And they are like oh yeah, I'm over here selling drugs and stuff. Most of my friends are, they dropped out like, some of my friends they dropped out middle school because they got knocked up or something. Um, it was like, everyone expected me to either get knocked up or out of all of my friends, then they all got knocked up or, you know."

Many PIs rely on sports as their only means to get into college. Without the promise of an athletic scholarship, many PI young adults are 
Tran, J., Wong, M., Wright, E.K., Fa'avae, J., Cheri, A., Wat, E., Camacho, K.L., \& Foo, M.A. / Californian Journal of Health

not informed about the alternative ways to get into school, thus, making it easier to delay or give up on pursuing an education.

"I didn't really have a main support person but the one thing that I relied on the most my four years in high school was sports and it was football because a lot of us rely on football...a lot of us go on to college without the knowledge and we're just playing ball, but we don't ever have a backup plan."

"But uh, you know like uh, I think for schoolwise like uh us Polynesians look at sports taking us to the next level. They, they forget about the you know the, the paperwork, the you know the studying' and all that, like you know, they think that, that by uh, you know like uh, like proving them that sports or that image you know like uh and burying yourself in that, they forget all the other stuff."

Miyamoto and Lee and Kumashiro discuss how there is a lack of understanding of PI students and their cultures and this leads to stereotypes that inform young adult identity. Often, educational attainment is not associated with this identity, as noted by participant comments above.

Informants all felt that their social, environmental and economic conditions made it challenging to succeed in education. In addition, many PI young adults were challenged with having to establish and work through their cultural and personal identity issues while combating existing stereotypes of PIs.

These key themes were shared in the key informant interviews and focus groups, reflecting a myriad of factors that influence and impact PI young adults in their educational access.

\section{Discussion}

The young adult needs assessment was an enriching and empowering process. In doing our research, we were able to encourage the voices of our young adults to be a part of the efforts that inform education and health care, in terms of making health and health-related careers available to PI communities. This effort reflects a community based, driven and engaged needs assessment process. Key areas of concern reflected in existing research (Ah Sam and Robinson, 1998; Onikama and Colleagues, 1998; Tsutsumoto, 1998; Kawakami, 1990; Kao and Thompson, 2005; Lee and Kumashiro, 2005; and Miyamoto, 2005) were reinforced by Southern California young adults. Socioeconomic status, family, structure/ involvement, social support, culture, educational resources and support, and stereotypes and identity were key themes shared by PI young adults from Los Angeles, Orange and San Diego counties. While the themes associated with the challenge in educational attainment are not that different from those found in other groups and PIs in Hawai i, it is important to document these factors for young adults in Southern California. This group had not been previously studied and had not been engaged in the process to improve access to education and health care. Findings from this needs assessment will help to inform the development of a pipeline program focusing on PI young adults by building confidence and pride, reducing economic barriers, and providing social support to ensure access to higher education and health career opportunities.

As expressed by PI young adults firsthand, there are a host of environmental and social factors that make it challenging to attain higher education in health related careers. Addressing these challenges will involve a multilevel approach- structural, systemic, and policy level changes in the surrounding environment. Utilizing the spectrum of prevention, a program was proposed to address the educational barriers for PI young adults, particularly in Southern California (Cohen and Swift, 1999). Initially developed as a model for injury prevention, Cohen and Swift designed a comprehensive approach that ensures success at multiple levels. Recommendations for the plan were based on input from young adult interviews and focus groups. A pipeline type program, developed through PIHCPP, will provide culturally appropriate and tailored support to PI youth and young adults by building self confidence and pride, reducing economic barriers, providing 
Tran, J., Wong, M., Wright, E.K., Fa'avae, J., Cheri, A., Wat, E., Camacho, K.L., \& Foo, M.A. / Californian Journal of Health

mental health and social support, providing PI youth and young adults access to higher education opportunities, mentorship and training as well as exposing PI youth and young adults to health career opportunities.

PIHCPP addresses the dearth of Pacific Islanders in health and health-related professions by addressing many of the concepts presented in this study, presented as challenges in access to higher education. In order to create a diverse health care workforce, to help address the burgeoning disparities in health among PI communities, we must first address access to higher education for our youth and young adults. PIHCPP proposes a model to look at the various levels that impact access to and matriculation from higher education for PI youth and young adults. The model must examine the individual level, engage community (including educators), educate community, and foster coalitions and networks. These efforts will help, to change organizational practice regarding the recruitment and retention of PI students in higher education, and lead to policy and legislative change to increase PIs in higher education and the health care workforce. The following is the proposed model for a PI pipeline in Southern California:

\section{Strengthening Individual Knowledge and Skills}

- Share educational information and resources with PI youth and young adults so they know what resources are available and can make an informed decision.

$\circ$ Outreach and engage students by going to them to share resources.

- Provide venues for PI students to meet each other, learn about the value of education, steps to pursue a higher education, and how to navigate the educational system.

- Provide educational opportunities for PI youth and young adults to learn about PI history and contributions in the United States, especially in health and education (e.g. cultural awareness and migration history).

- Seek and develop opportunities to actively/proactively engage students in pipeline programs and activities.
- Recruit students to serve as mentors.

o "Train the Trainers"- Train students, who have embraced and experienced the value of education- to share resources with other students.

\section{Promoting Community Education}

- Engage and help parents and social support networks of youth and young adults (beyond parents) to understand the educational process.

- Provide resources and informational workshops addressing the value of education as well as ways in which they can engage and be supportive.

\section{Educating Providers}

- Continue to educate providers (high school and college administrators/officials, academic counselors, financial aid officials) of the widening gap between enrollment of Pacific Islanders in high schools/colleges and the lack of Pacific Islanders in the health workforce.

- Educate providers about how to provide services in a culturally competent and sensitive manner.

\section{Fostering Coalitions and Networks}

- Form partnerships among academic institutions, community based organizations, high schools, and key stakeholders and administrators who will commit to helping to increase the number of Pacific Islanders in the healthcare workforce and in higher education.

- Develop and convene a community advisory board - comprised of key leaders and stakeholders within the community - to develop and oversee the development of pipeline-related initiatives and activities.

- Build and develop community support around the well-being and advancement of PI youth and young adults (not only focused on educational opportunities but social and neighborhood environment).

\section{Changing Organizational Practices}

- Work with financial aid organizations to recognize and assist Pacific Islander students in accessing higher education 
Tran, J., Wong, M., Wright, E.K., Fa'avae, J., Cheri, A., Wat, E., Camacho, K.L., \& Foo, M.A. / Californian Journal of Health Promotion 2010, Special Issue (Cancer Control), 23-38

Table 2

\section{PIHCPP Model and Activities}

\begin{tabular}{|c|c|}
\hline $\begin{array}{l}\text { Strengthening Individual } \\
\text { Knowledge and Skills }\end{array}$ & $\begin{array}{l}\text { - } \\
\text { - } \quad \text { Fecruit a cohort of Pacific Islander students: } \\
\text { and hands-on experience in a community or research setting to better understand } \\
\text { health disparities and efforts to address these issues: } \\
\text { - Currently reviewing applications for the second cohort of students - expecting } 13 \\
\text { students starting Summer } 2010 \text { to participate in a comprehensive fellowship } \\
\text { program including exposure and hands-one experience in a community and research } \\
\text { setting to understand health disparities and efforts to address these issues; receive } \\
\text { academic support through workshops; and receive psychosocial support through } \\
\text { mentorship } \\
\text { Participate in community events to share this program and its goals - e.g. Youth } \\
\text { Leadership Summit Fall 2009; lecture in Asian American and Pacific Islander } \\
\text { Studies courses sharing resources and highlighting Pacific Islander health disparities } \\
\text { (4 courses at UCLA and CSUF over the past year) }\end{array}$ \\
\hline $\begin{array}{l}\text { Promoting Community } \\
\text { Education }\end{array}$ & $\begin{array}{l}\text { - Conducted a Parent Night } 2009 \text { at Magnolia High School sharing PIHCPP student } \\
\text { presentations from the first cohort } \\
\text { - Community forum to share findings from interviews and focus groups with } \\
\text { community in Long Beach and San Diego } \\
\text { - Dissemination of the PIHCPP Needs Assessment report to community leaders and } \\
\text { educational leaders locally, statewide, and nationally }\end{array}$ \\
\hline Educating Providers & 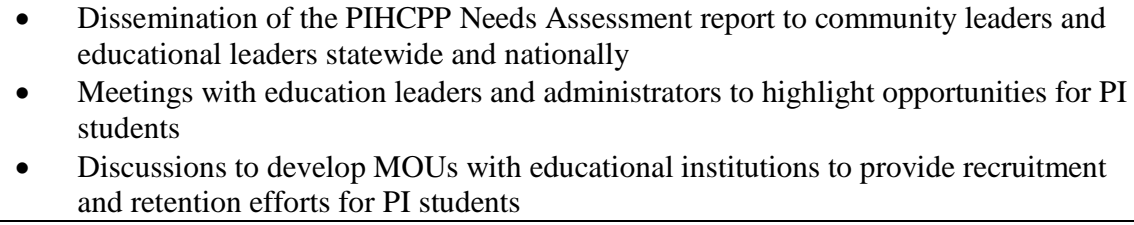 \\
\hline $\begin{array}{l}\text { Fostering Coalitions and } \\
\text { Networks }\end{array}$ & $\begin{array}{l}\text { - Maintained Advisory Board of community and education leaders to achieve mission } \\
\text { of PIHCPP } \\
\text { Discussions to develop MOUs with educational institutions to provide recruitment } \\
\text { and retention efforts for PI students } \\
\text { - } \quad \text { Momentum from community support for the well being and advancement of PI } \\
\text { young adults - PIHCPP mission integrated into work of partner agencies } \\
\text { Linking OCAPICA's College Bound afterschool program for Pacific Islander } \\
\text { students at Magnolia High school with PIHCPP. The program seeks to increase the } \\
\text { number of Pacific Islander youth that will graduate from high school and then } \\
\text { successfully enter and graduate from college. Qualified students who participate in } \\
\text { the program can be funneled into the PIHCPP directly. } \\
\text { Leveraging resources from National Cancer Institute (NCI) to provide paid summer } \\
\text { research internships on cancer health disparities for Pacific Islander students }\end{array}$ \\
\hline $\begin{array}{l}\text { Changing Organizational } \\
\text { Practices }\end{array}$ & $\begin{array}{l}\text { - Work with community leaders and foundations to educate about PI youth and } \\
\text { discuss opportunities for students } \\
\text { - } \quad \text { Invited representatives from Gates Millennium Foundation to learn more about } \\
\text { students } \\
\text { - } \quad \text { Encourage students to apply to the APIA Scholarship Opportunity } \\
\text { Provide scholarships to PI students for health and health-related careers through } \\
\text { CDC funded REACH US PATH for Women Center of Excellence to Eliminate } \\
\text { Health Disparities - sister project of PIHCPP }\end{array}$ \\
\hline $\begin{array}{l}\text { Influencing Policy and } \\
\text { Legislation }\end{array}$ & $\begin{array}{l}\text { - Dissemination of the PIHCPP Needs Assessment report to legislators and legislative } \\
\text { staff statewide and nationally } \\
\text { - Meetings with legislators and legislative staff to discuss educational opportunities } \\
\text { for PI students and health disparities }\end{array}$ \\
\hline
\end{tabular}


policy and/or infrastructural changes within the organization (e.g. focusing on scholarship and financial support).

- Work with college administrators and professors to develop initiatives and policies to increase Pacific Islander enrollment and offer resources and opportunities to Pacific Islander youth and young adults.

\section{Influencing Policy and Legislation}

- Work with funding organizations to strategically develop ways to increase advocacy efforts promoting higher education among Pacific Islanders.

- Meet with local and state legislators to provide information about PIHCPP and its potential positive impact on the Pacific Islander community

- Examine the value that Pacific Islander students bring to the university (e.g. through athletics) and discuss opportunities to link those benefits to student learning/academic benefits

This model integrates the voices heard from the key informant and focus group participants of our study. This also integrates feedback and dialogue from our Community Advisory Board to develop a culturally and linguistically sensitive pipeline program to promote PI youth and young adults in health and health-related careers. Since this study, 7 students have participated in the first cohort of individuals of the PIHCPP in the summer of 2009. This spectrum of prevention model continues to be tailored and adapted as we recruit our second cohort $(\mathrm{N}=13)$ of students for summer 2010. Table 2 lists some of the current activities of PIHCPP. In process is a curriculum, referred to as the PIHCPP Fellowship, integrating all aspects of this model, and focusing on the individual and interpersonal levels in working with students. Community engagement has led to networking and relationship building at the structural, systematic and policy level moving toward longer-term sustainable change.

While this was a successful endeavor to engage and involve community in addressing education and health careers there are limitations to consider when interpreting the findings. First, the study was conducted in a cross-sectional manner and only represents one point in time. While saturation was met through the focus groups, the study consisted of a non-probability sample, which cannot be generalizable to the broader population. Convenience sampling may have also yielded socially desirable responses from key informants, due to the prior relationships that lended to recruitment, reflecting bias. Future studies would benefit from a population based sampling methodology that follows a larger pool of subjects longitudinally and across a larger geographic area to assess similarities and differences that may be more generalizable.

\section{Acknowledgements}

Special thanks and acknowledgement for the generous support from The California Endowment, and special thanks to staff Sidharth Voorakkara and former staff Khushbindar Lally. Additional thanks to all the community leaders, members, and study participants who partnered with OCAPICA to ensure a community-based and driven effort to understand the need for access to education in health and health-care related fields among Pacific Islanders. Additional support provided by WINCART: Weaving an Islander Network for Cancer Awareness, Research and Training through funds from the National Cancer Institute's Center to Reduce Cancer Health Disparities, Grant Number U01CA11459 and REACH US PATH for Women (Promoting Access to Health for Pacific Islander and Southeast Asian Women) with support by Cooperative Agreement Numbers 5U58DP001006-02 and 5U58DP001006-03 from the Centers for Disease Control and Prevention. The contents are solely the responsibility of the authors and do not necessarily represent the official views of the NCI CRCHD or the CDC. 
Tran, J., Wong, M., Wright, E.K., Fa'avae, J., Cheri, A., Wat, E., Camacho, K.L., \& Foo, M.A. / Californian Journal of Health Promotion 2010, Special Issue (Cancer Control), 23-38

\section{References}

Ah Sam, ALF \& Robinson, NB. (1998). Pacific Islanders in Higher Education: barriers to Recruitment and Retention. Pacific Educational Research Journal; 9(1); 39-49.

Benham, MKP. (2006). A challenge to Native Hawaiian and Pacific Islander scholars: what the research literature teaches us about our work. Race Ethnicity and Education 2006 March, 9(1):29-50.

Bernard R. Research methods in anthropology: Qualitative and quantitative approaches. 2006. Oxford: Altamira Press.

Cohen L and Swift S (1999). The Spectrum of Prevention: Developing a Comprehensive Approach to Injury Prevention. Injury Prevention 1999, 5,203-207.

Denzin NK, Ye L. Handbook of qualitative research - 2nd Ed. 2000. Thousand Oaks, CA: Sage Publications.

Fong M \& Aitaoto, N. (2008). A community-participatory model to develop educational materials for Pacific Islanders. Recorded presentation. American Public Health Association Public Health and Human Rights APHA 134th Annual Meeting and Exposition. 2006 Nov 4-8 Boston, MA. Retrieved on January 18, 2008: http://apha.confex.com/apha/134am/techprogram/paper_126257. htm

Health Resources and Services Administration. The Rationale for Diversity in the Health Professions: a Review of the Evidence. Rockville, MD: US Department of Health and Human Services; 2006.

Hughes CK \& Higuchi P. (2004). Ka Lokahi Wahine: a culturally based training for health professionals. Pacific Health Dialogue, 11(2),166-9.

Kao G \& Thompson JS. (2003). Racial and ethnic stratification in educational achievement and attainment. Annual Review of Sociology, 29; 417-443.

Kawakami, AJ (1990). Young Children and Education in the Pacific: A Look at the Research. Pacific Resource for Education and Learning, November 2001

Lai E \& Arguelles D. eds. (2003). The New Face of Asian Pacific America: Numbers, Diversity \& Change in the 21st Century. Los Angeles, CA; UCLA Asian American Studies Center Press.

Lee SK \& Kumashiro KK (2005). National Education Association: A Report on the Statue of Asian American and Pacific Islanders in Education: Beyond the "Model Minority" Stereotype. National Education Association of the United States, Human and Civil Rights, Washington DC, 2005.

Marcelin G, Goldman L, Spivey WLL, Eichel JD, Kaufman F \& Fleischman AR. (2004). Junior Fellows Program: Motivating Urban Youth towards Careers in Health, Science, and Medicine. Journal of Urban Health 2004 Sep, 81(3),516-23.

Marshall SF, Ziogas A, \& Anton-Culver H. (2008). OC Komen Affiliate \& UCI Data Project: breast cancer incidence $\&$ prevalence in orange county, monograph II - disparities in breast cancer mortality in orange county (Journal No. Monograph 2). Irvine, California: University of California, Irvine.

Miles MB, Huberman AM. Qualitative data analysis: An expanded sourcebook. 1994. Thousand Oaks, CA: Sage Publications.

Miller BA, Kolonel LN, Bernstein L, Young Jr JL, Swanson GM, West D, Key CR, Liff JM, Glover CS, Alexander GA, et al. editors (1996). Racial/ethnic patterns of cancer in the United States 19881992. Bethesda, MD: National Cancer Institute; 1996. NIH Pub. No 96-4104. Accessed on June 22, 2007 from http://www-seer.ims.nci.nih.gov/Publications/REPoC

Mishra SI, Luce-Aoelua P, Wilkens LR, \& Berstein L. (1996). Cancer among American-Samoans; Sitespecific incidence in California and Hawaii. International Journal of Epidemiology, 25(4),713721.

Miyamoto JK. (2005). Community needs as perceived by Pacific Islander School Personnel. Master's Thesis; California State University, Long Beach.

Office of Minority Health. Quick Facts. Accessed on January 3, 2008 http://www.omhrc.gov

Onikama DL, Hammond OR \& Koki S. (1998). Family Involvement in Education: A Synthesis of Research for Pacific Educators. Pacific Resource for Education and Learning Research Series. 
Tran, J., Wong, M., Wright, E.K., Fa'avae, J., Cheri, A., Wat, E., Camacho, K.L., \& Foo, M.A. / Californian Journal of Health Promotion 2010, Special Issue (Cancer Control), 23-38

O'Sullivan HM \& Lum K. (2001). Herbal medicine on the rise: the case of 'awa. Pacific Health Dialogue, 2,280-7.

Palafox NA, Johnson DB, Katz AR, Minami JS, \& Briand K. (1998). Site specific cancer incidence in the Republic of the Marshall Islands. Cancer; 83(S8),1821-1824.

Pearsall P. (2007). Contextual cardiology; what modern medicine can learn from ancient Hawaiian wisdom. Cleveland Clinical Journal of Medicine, 74(S1)S99-104.

Ribeiro MA \& Harrigan RC. (2006). A literature review on Complementary and Alternative Medicine for the treatment of breast cancer: Hawai'i. Hawaii Medical Jouranl, 65(7); 190-7.

Santos L, Mokuau N, Abrigo L, Braun KL, Tsark JU, Mackura G, Kuhaulua R, \& Chong CD. (2001). 'Imi Hale: establishing an inheritance for Native Hawaiians on cancer awareness, research and training. Pacific Health Dialogue, 2, 436-45.

Strauss A, Corbin J. Basics of qualitative research: Grounded theory procedures and Techniques. 1990. London: Sage Publications.

Strayhorn G \& Demby K. (1999). Do pre-admission programs make a difference in the enrollment of underrepresented-minority students at US medical schools? Acad Med 1999 April 74(4):431-4.

Tsark, JA. (2001). A participatory research approach to address data needs in tobacco use among Native Hawaiians. Asian American Pacific Islander Journal of Health, 9(1), 40-48.

Tsutsumoto, TS. (1998). Higher Educational Perspectives: Through the Narratives of Samoan College Students. Master's Thesis; UCLA.

UCLA Asian American Studies Center - Census Information Center (2007). UC AAPI Policy Initiative. Analytical Brief of New Census Data. Pacific Islanders Lagging Behind in Higher Educational Attainment. November 14; Los Angeles, CA.

Unequal Treatment: What Health Care System Administrators Need to Know About Racial and Ethnic Disparities in Healthcare, Institute of Medicine (March 2002).

Sullivan Commission on Diversity in the Health Workforce. Missing Persons: Minorities in the Health Professions. Washington, DC 2004.

U.S. Bureau of the Census. American Community Survey Reports, 2007. The American Community Pacific Islanders: 2004.

US Bureau of the Census. American Fact Finder, 2000, SF3, P148E. Available at: http://www.census.gov. Accessed March 1, 2009.

US Bureau of the Census. American Fact Finder, 2000, SF4. Available at: http://www.census.gov. Accessed March 1, 2009.

US Bureau of the Census. American Fact Finder, 2000, SF4, PCT86. Available at: http://www.census.gov. Accessed March 1, 2009

$\underline{\text { Author Information }}$

*Jacqueline H. Tran, MPH

Orange County Asian and Pacific Islander Community

Alliance (OCAPICA)

12900 Garden Grove Blvd., Suite 214A

Garden Grove, CA 92843

Telephone: (714) 636-9095

Fax (714) 636-8828

Email: jtran@ocapica.org

Michelle Wong, MPH

Orange County Asian and Pacific Islander Community

Alliance (OCAPICA) 
Tran, J., Wong, M., Wright, E.K., Fa'avae, J., Cheri, A., Wat, E., Camacho, K.L., \& Foo, M.A. / Californian Journal of Health Promotion 2010, Special Issue (Cancer Control), 23-38

Erin Kahunawaika'ala Wright, Ph.D., M.Ed.

University of Hawai i- Manoa

Joe Fa'avae

Orange County Asian and Pacific Islander Community

Alliance (OCAPICA)

Ashley Cheri

Orange County Asian and Pacific Islander Community

Alliance (OCAPICA)

Eric Wat, MA

Special Service for Groups, Research and Evaluation Unit

Keith L. Camacho, Ph.D., MA

University of California, Los Angeles

Department of Asian American Studies

Mary Anne Foo, MPH

Orange County Asian and Pacific Islander Community

Alliance (OCAPICA)

* corresponding author 